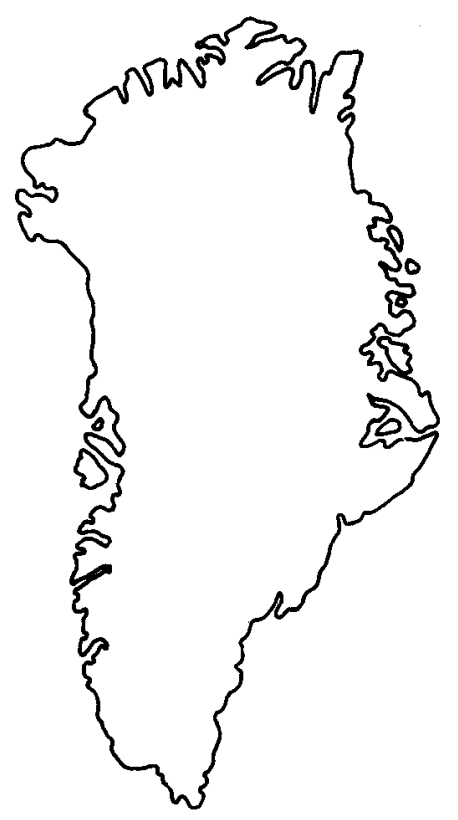

\title{
Close-range geological photogrammetry studies: field and laboratory procedures with examples from prograde granulite facies orthogneisses, Kerala, South India
}

\author{
Adam A. Garde
}

\begin{abstract}
Precambrian orthogneisses exposed in quarries in the Palghat Gap, Kerala, South India, were photographed for use in geological photogrammetry studies with a $35 \mathrm{~mm}$ (small frame) hand-held camera. Local ground control was provided by simple means: hand level, geological compass and $2 \mathrm{~m}$ rule. The practical procedure of photography and acquisition of ground control data is described. The stereoscopic photographs, which show complicated field relations in gneisses with prograde, transitional amphibolite to granulite metamorphic facies relations, were studied using multi-model photogrammetry (see Dueholm, 1992) and an analytical plotter. The estimated standard deviations in the stereo models of scale, azimuth and levelling were $\pm 2 \%, 2^{\circ}$ and $5^{\circ}$, respectively, but the precision was very good (less than $1 \mathrm{~cm}$ ). Outcrop maps were drawn with an on-line plotter at scales varying from 1:25 to 1:200 with contour intervals between 5 and $100 \mathrm{~cm}$. The plot data were transferred, edited on a Macintosh computer and made ready for publication with a vector-based graphics application.
\end{abstract}

A. A. G., Geological Survey of Greenland, Øster Voldgade 10, DK-1350 Copenhagen K, Denmark.

This paper describes the use of hand-held, close range stereoscopic photographs in a study of Precambrian orthogneisses, which display prograde transitional amphibolite to granulite facies metamorphism. The study was initiated in order to carry out experiments with geological photogrammetry of small, complicated geological outcrops using the multi-model method (see Dueholm, 1992), and to compare this prograde type of metamorphism with granulite facies metamorphism associated with retrogression in southern West Greenland (Garde, 1990). The paper illustrates how the multimodel photogrammetrical method can be used to go from a simple field sketch or photograph to an accurate presentation to scale and in three dimensions of a complex geological outcrop, and try to understand what one actually sees. The field work took place in the central part of the Palghat Gap area in Kerala, South India (Fig. 1) during three weeks in December 1989, in the company of G. R. Ravindra Kumar and Venkatesh Raghavan (Centre for Earth Science Studies, Trivandrum) who had previously identified the patchy prograde metamorphic transitions from amphibolite to gra- nulite facies in the area. The remainder of the work was done in Copenhagen.

The Palghat Gap area is intensely cultivated with paddy fields, and the only bedrock exposures are found in stone quarries on the flanks of low hills which emerge here and there from the flat countryside. The quarries are operated by hand to provide local road material. Only the active quarries provide rock exposure of sufficient quality to display lithological details, because such features become invisible within two or three years due to weathering in the warm and humid climate; in situations like this it is particularly desirable to obtain good visual documentation, and preferably in three dimensions. The field work involved detailed investigations by foot of outcrops in many quarries, and stereoscopic photography (on colour slides) with subsequent geological photogrammetry was used extensively as documentation.

\section{General geology}

The Palghat Gap lies within the granulite terrain in 


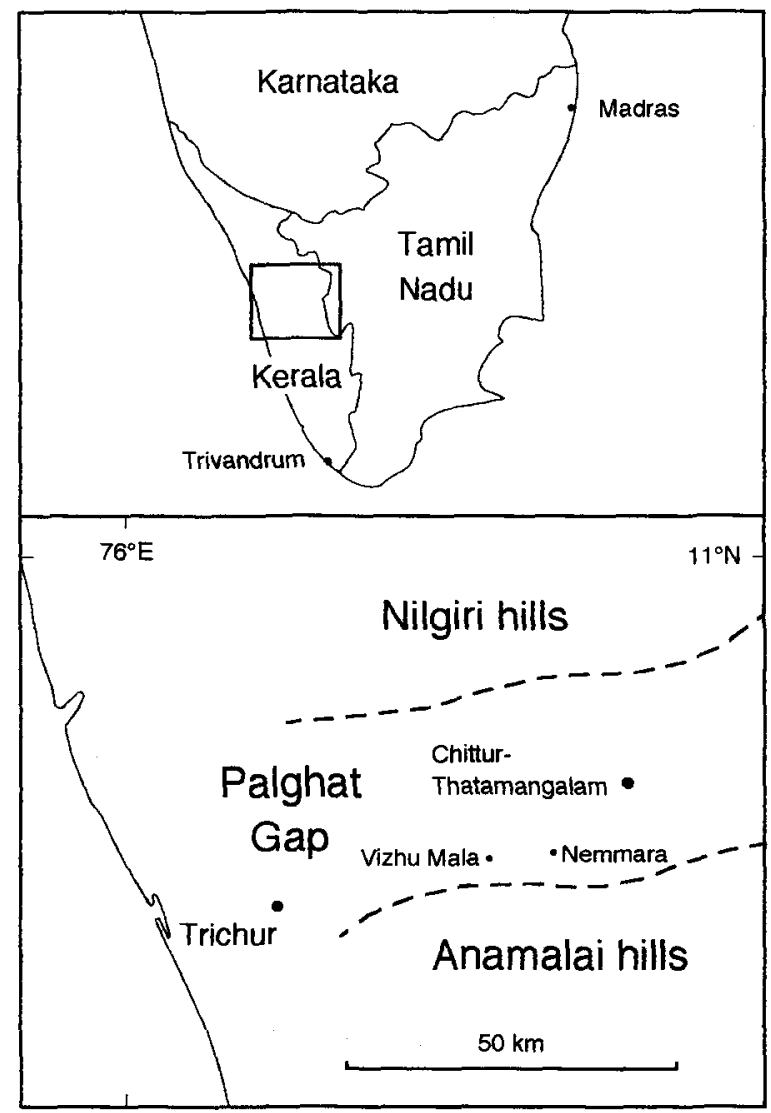

Fig. 1. Index map of South India with locations of the quarries at Nemmara and Vizhu Mala in the Palghat Gap.

the southern Indian shield, just south of the Archaean granite-greenstone terrain (Radhakrishna, 1983). As the name implies, the Palghat Gap is a low-lying tract, bounded by east-west trending shear zones with the Anamalai hills to the south and the late Archaean Nilgiri hills to the north (Raith et al., 1990), in which elevations reach up to $c .2500 \mathrm{~m}$ above sea level. The physiography of the Palghat Gap was discussed by Subramanian \& Muraleedharan (1985). The area consists of high-grade quartzo-feldspathic orthogneisses with occasional enclaves of supracrustal rocks. The age of emplacement of the orthogneisses is uncertain, but is thought to be late Archaean or Proterozoic. It is possible that Pan-African events also affected the area; Soman et al. (1990) recently published Pan-African biotite and muscovite K-Ar ages ( 484 to $512 \mathrm{Ma}$ ) from late pegmatites within the Palghat Gap. Ravindra Kumar \& Raghavan (1992) discussed granulite facies metamorphism in the Palghat Gap with examples from the same localities as those described in this paper; however their geological interpretations of the quarry outcrops are at variance with those presented here.

\section{Geological photogrammetry with local reference points and minimum ground control}

The geological scenes were quarry floors and inclined rock faces ranging from $c .10$ to $150 \mathrm{~m}^{2}$ in area (an example is shown on Fig. 3a), which displayed complex lithological and structural relationships between various rock components (see below), and frequently also metamorphic transitions between amphibolite and granulite facies. In the quarries, rough field sketches with preliminary interpretations were made, the rock types were identified, and some of the localities were photographed in stereo as explained below.

\section{Ground control and photography}

Flexibility and ease of working on foot in the quarries were considered more important than maximum accuracy. Thus the camera was held in the hand, and only simple means were used to obtain ground control data. Available topographic maps were of poor quality and gave only the approximate locations of the quarries; however, the precise geographical coordinates and elevations of each photographed locality were not important in the present study.

For practical purposes the ground control data necessary for orientation of the stereoscopic models, i.e. information about scale, levelling, northing and local reference points, can be combined into a few geometrical elements. A data set sufficient for orientation of one model may thus consist of two points with known (absolute or local) coordinates and elevations within the stereoscopic space, as well as the orientation (direction of view and tilt angle) of the camera axis for one of the two photographs. Other combinations of points and angles can also be used.

Fig. 2 shows a typical photographic scene in a quarry and the acquisition of ground control data for model orientation. A $2 \mathrm{~m}$ rule (occasionally replaced by a $20 \mathrm{~m}$ measuring tape), a Silva geological compass and a handheld level sufficed for the measurements. The rule was laid horizontally on the outcrop (using a hand level), and its direction was measured to $\pm 2^{\circ}$ with the geological compass. The tilt angle of the camera and the azimuth of its axis were measured to $\pm 5^{\circ}$; in most cases the camera axis (direction of view) was horizontal, and camera axes of related exposures were parallel to each other. In the example of Fig. 2 the above mentioned two points with relative coordinates and known height difference are provided by the two levelled ends of the rule and its compass direction (the points $x$ and $y$, and angle $a$ on Fig. 2); the direction of view and tilt angle of the camera are the angles $b$ and $c$ (Fig. 2). Using these 
simple procedures the stereoscopic photography of a geological outcrop could be achieved in about $10 \mathrm{~min}-$ utes. Most often the geological scene was contained in a single stereoscopic model with $c$. $70 \%$ overlap between the two exposures.

Besides showing features related to geology, interpretation in the DSR-15 instrument, and means of presentation (discussed later), Figs 3-7 also illustrate different photography situations; the rule was sometimes included in the drawings in the place where it was laid for ground control. Figs 3 and 6 were taken at close hand, with the camera tilted $c .25^{\circ}$ downwards from horizontal towards a sloping quarry floor at the feet of the geologist. These figures show much geological and topographical detail. Figs 4 and 7 were taken with horizontal camera axis towards inclined quarry faces, and Fig. 5 towards a steep quarry face with local overhanging parts, with the camera axis tilted slightly upwards.

All photographs were taken with an Olympus OM-2 small frame $(35 \mathrm{~mm})$ camera, mounted with a $f 2.8,35$ $\mathrm{mm}$ wide angle lens focused at infinity. The distance from the camera to the scene was generally between 3-10 m. Kodachrome 64 ASA diapositive film was chosen due to its proven long-term stability and good resolution. Conditions of exposure were typically $1 / 250 \mathrm{sec}$. at $f 5.6$. or $1 / 125 \mathrm{sec}$. at $f 8$ when parts of the scene were closer than $3 \mathrm{~m}$.

\section{Orientation in the DSR-15 instrument}

The field camera had previously been calibrated (see Dueholm \& Garde, 1985; Dueholm, 1992). The diapos-

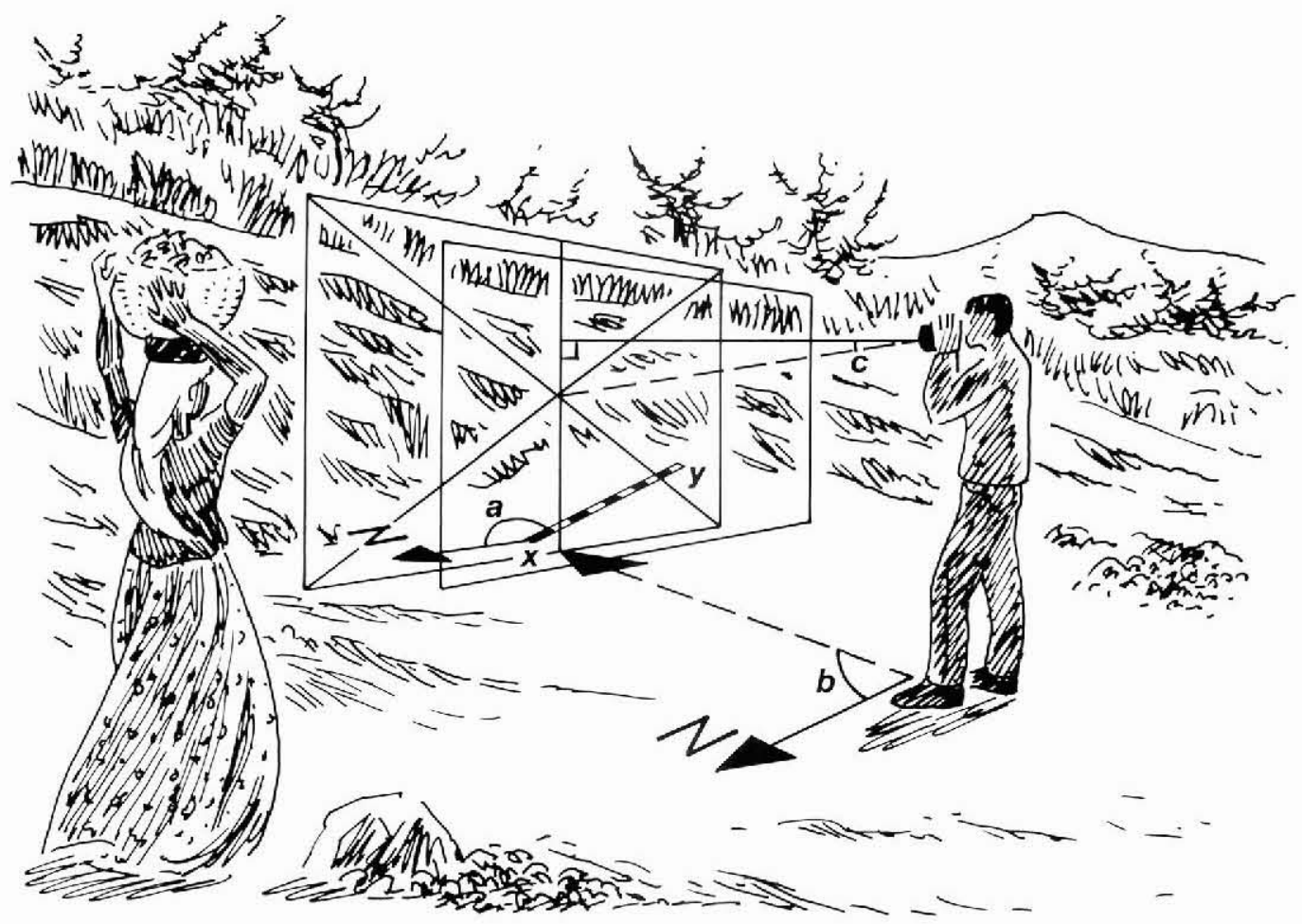

Fig. 2. Acquisition of field data - five geometrical elements numbered (1) to (5) in this text - for orientation of stereo models with local geographical reference points. The sketch shows photography of two pictures with $c .70 \%$ overlap, for later orientation of one model with the multi-model software. The rule with end points $x$ and $y$ provides (1) scale, namely the distance between its two ends $x$ and $y$. (2) levelling in one direction (the two ends of the rule $x$ and $y$ are placed at the same elevation by means of the hand level), and (3) the azimuth of the distance $x-y$ (the angle $a$ between the rule and north, measured clockwise from north with the compass). The angles $b$ (element 4 ) and $c$ (element 5) are related to the camera position in one of the two pictures, in this case the left one. The angle $b$ provides direction of view (element 4), measured clockwise from north (in this case c. $90^{\circ}-$ as opposed to $c$. $\left.270^{\circ}\right)$. This angle is redundant with respect to angle $a$, but in practice useful for the orientation. The tilt angle $c$ between the camera axis and horizontal provides additional levelling (element 5 ) in the direction of the camera axis. The tilt angle, which is $c$. $15^{\circ}$ downwards in the shown example, can be measured with the clinometer of the geological compass. It is often convenient to keep the camera axis horizontal, and in that case it can be controlled by finding an item at eye level on the quarry face with the hand level, and then point the camera in this direction. 

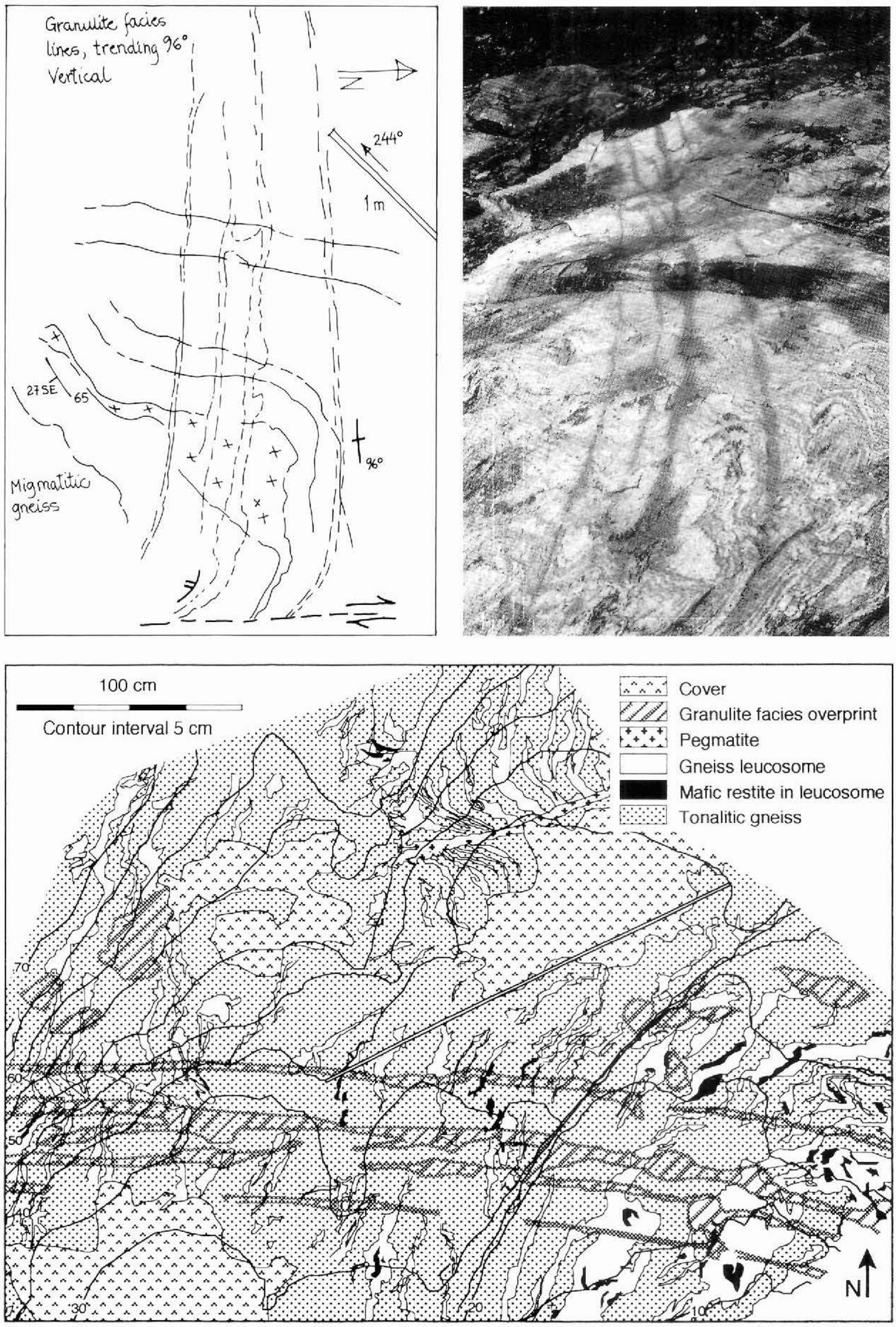


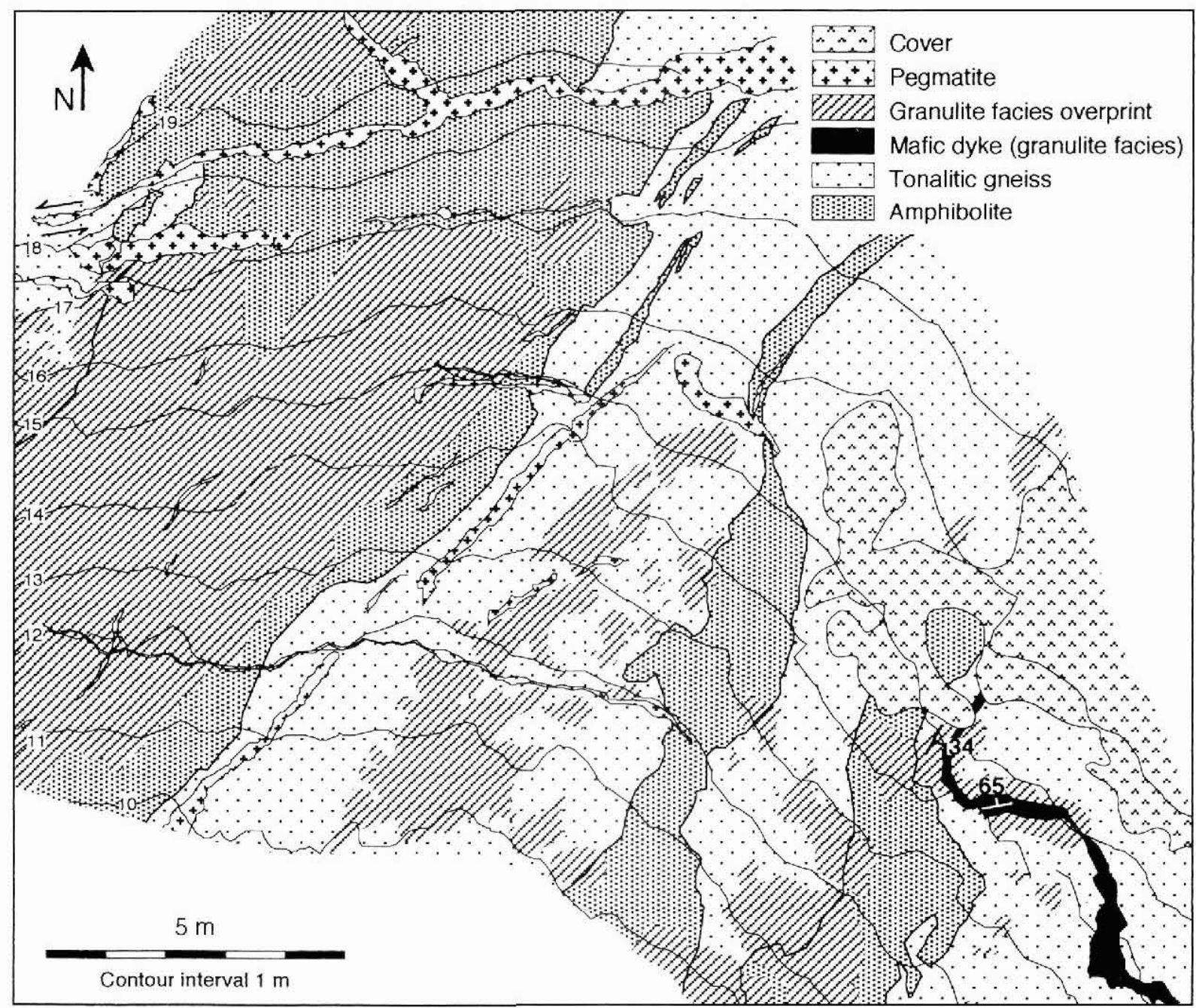

Fig. 4. Map of a sloping quarry face at Nemmara, scale 1:125, photographed with horizontal camera axis. The outcrop displays a granulite facies overprint controlled by mafic lithologies (amphibolite and mafic dyke), and less extensive, patchy development of granulite facies in tonalitic gneiss. Left-lateral displacement has occurred along a late pegmatite (upper left).

itives were mounted on templates measuring $240 \times 260$ $\mathrm{mm}$, each with space for 20 small frame exposures (see Dueholm, 1992), and the stereo models were orientated using the multi-model program described by Dueholm

Fig. 3. Quarry floor at Nemmara. (a) Photograph of the locality, (b) Ficld sketch, (c) Map at scale 1:25 (the rule is $2 \mathrm{~m}$ long). The three parts of Fig. 3 illustrate steps between the actual outcrop, the geological field sketch with notes, and the final interpretation drawn to scale. In terms of geology the figure shows thin east-west trending stringers of granulite facies, which overprint and cut earlier folds in migmatitic gneiss. Nearby (just east of the frame on Fig. 3c), the granulite facies stringers are themselves deformed along a minor shear zone injected by pegmatite.
(1992); actually, the geological scenes presented on Figs 3-7 consisted of just one model each. The orientations were generally easy to perform because no external ground control points need be transferred. The estimated standard deviations of scale and azimuth were \pm $2 \%$ and $\pm 2^{\circ}$, respectively, whereas the levelling was less accurate - in some cases with standard deviations estimated at up to $\pm 5^{\circ}$. This error could have been reduced, if necessary, by use of a levelled tripod or a levelling instrument, or by identification of other horizontal or vertical objects besides the rule (such as e.g. small pools of water or suspended plumblines). The relative error of measurements with the analytical plotter, which is often of more interest for the geologist than the standard deviation of scale, azimuth and levelling, 
was less than $1 \mathrm{~cm}$ in the orientated models used in the present study.

\section{Acquisition of data in the DSR-15 instrument}

Contour lines and other topographical data, as well as geology (described under a separate heading below), were drawn by means of the DSR-15 instrument linked to an on-line plotting table as described by Dueholm (1992). The data could be presented as appropriate in each case as undistorted maps, sections or perspectives, and at any desired scale. The data were simultaneously stored as lines and points in data files.

\section{Presentation of plots from the analytical plotter using commercial computer software}

The multi-model program only allows slow, sequential editing of the data files produced with the analytical plotter. Therefore the digital plot data were transferred to a Macintosh computer for experiments with editing and fabrication of publication-ready illustrations; procedures and general experience during these experiments are outlined in the following.

On the Digital VAX computer attached to the DSR-15 instrument, the plot data were transformed with the multi-model photogrammetry software to the standardised Danish DSFL data exchange format for geographical information systems, and transmitted to a Macintosh computer via the commercial interface applications Kermit and Versaterm Pro. The data were then translated to the PICT graphics format for Macintosh with the program MacKort written at the Institute of surveying and photogrammetry. MacKort allows change of scale and insertion of reference points or grids (useful if several data files from one area are translated).

All further work was done with a commercial vectorbased graphics application installed on a Macintosh LC computer, and printed on an ink-jet printer; it was found that computers smaller than a Macintosh LC or equivalent cannot handle this type of data at a reasonable speed. In order to make the computerised editing and redrawing worthwhile compared to hand work, the graphics application should be simple to use and fast, and therefore large CAD or GIS applications for industrial purposes are not considered suitable.

The graphics application should be able to link various parts of a drawing so that they can both be easily identified and manipulated selectively. The application should also be capable of cutting a line into two, as well as joining up several individual lines to form a single new line. This is desirable because data transferred from DSR-15 plots mostly consist of individual lines, since interpretations with the analytical plotter are made line by line. In particular, graphics applications generally cannot (as per December, 1991) insert patterns into areas which are bounded by several individual lines - and that is very often required in geological drawings.

Figs 3-7 were all made with the application Claris MacDraw II, which was adequate in many respects, easy to use and fast. It has a good layer facility, which in combination with the Macintosh 'clipboard' copy feature makes it easy to keep the drawing organised. A major drawback of MacDraw II (and its recent successor MacDraw Pro) is the inability to cut and join lines. This latter feature is available in a user-friendly form in e.g. Canvas 3 by Deneba Systems, but at the expense of a slower overall performance. Both applications have good text facilities which allow in situ editing of text.

\section{Visual documentation and geological analysis of the quarry exposures with the analytical plotter}

Figs 3-7 demonstrate the use of close-range handheld photogrammetry in the study of small, complex geological outcrops. Based on the geological information collected in the field as quick sketches, notes and remarks about rock types, the geological interpretation could be continued in the DSR-15 instrument. The three-dimensional view, colours, and easy alternation between overview $(5 \times$ magnification $)$ and high magnification $(20 \times)$ meant that many geological features could be discerned which had originally been overlooked in the field. Relationships between lithologies, structures and metamorphic transitions, which at first looked chaotic, could be analysed and put together step by step like a puzzle, until patterns emerged and the sequence of geological events on each outcrop could be established. Fig. 3 shows an overview photograph, a field diary sketch and the DSR-15 interpretation of the same outcrop for comparison. The instrument also enabled quantification of the size and orientation of geological structures, and the direction and amount of dis-

Fig. 5. (a) Map at scale 1:100 and (b) perspective view (scale approximately $1: 125$, direction of view $330^{\circ}$ ) of a quarry face at Vizhu Mala, illustrating the use of two different projections based on the same interpretation. In this quarry only the granite and pegmatite have amphibolite facies parageneses; the relationships between the granite and the granulite facies event are ambiguous (see the main text). The irregular dyke shape to the left is a topographic effect. The rule (lower right) is $2 \mathrm{~m}$ long. 

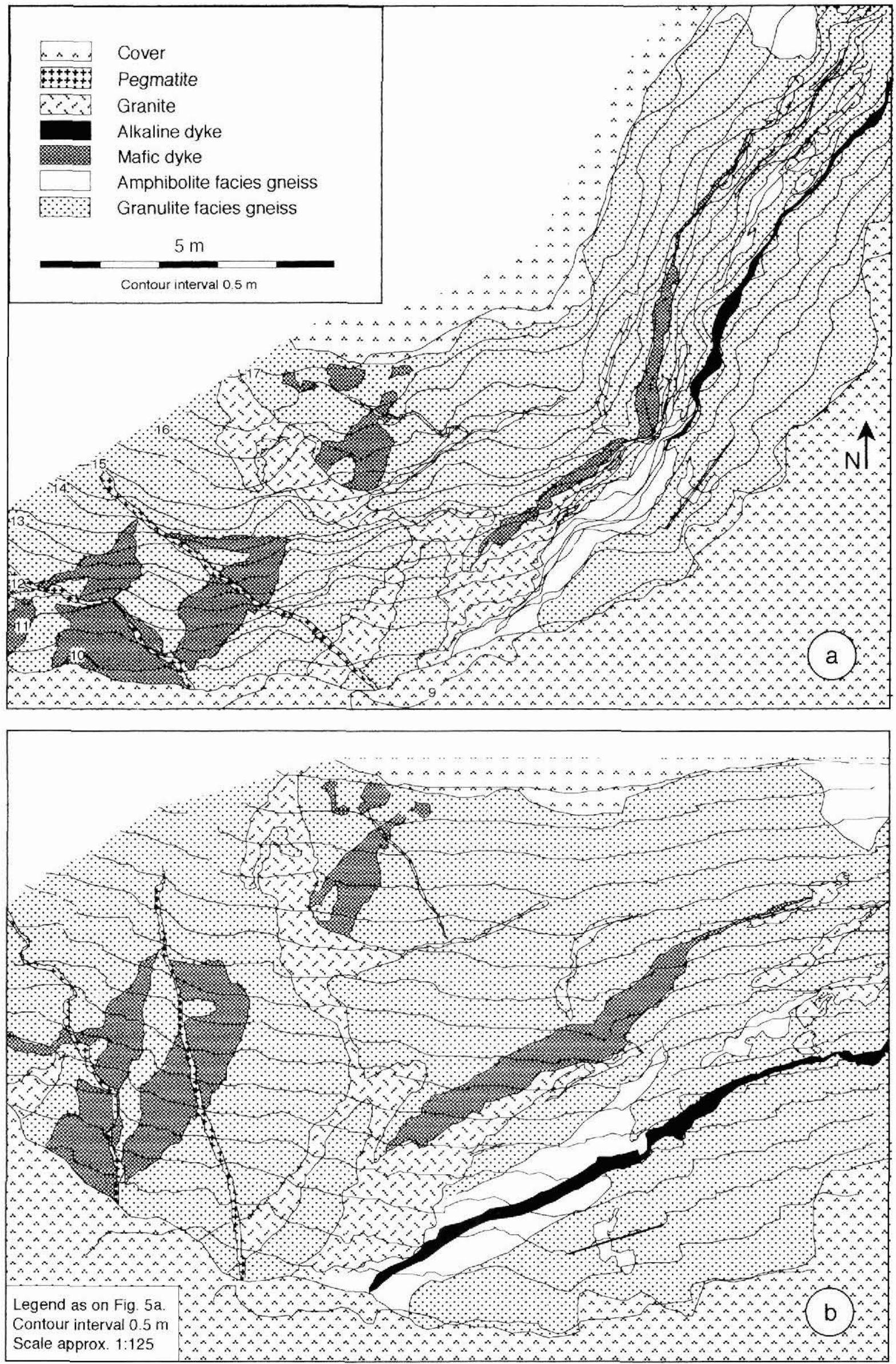
placement along small faults. In addition it was possible to choose the most appropriate presentation in each case. The examples vary in scale from 1:25 to $1: 200$, with corresponding contour intervals between 5 and 100 $\mathrm{cm}$. In contrast to most other examples shown in the present volume, which are profiles, Figs 3-7 in this paper are small geological maps (plan views), except Fig. $5 b$ which is a perspective view.

All the outcrops shown on Figs 3-7 possess similar protoliths and essentially exhibit the same geological evolution, with local variations. The main rock type is a migmatised tonalitic orthogneiss, and as shown on Figs 3 and 6 structures related to partial melting, segregation of leucocratic layers and veining at a centimetre scale could be mapped in great detail with the analytical plotter. The detailed mapping with the analytical plotter reveals an episode of plastic deformation, as illustrated by the small folds outlined by leucosome in Fig. 3. Enclaves and fragments of amphibolite and dioritic orthogneiss in the main gneiss can be seen on Figs 4 and 6 , and Figs 4-5 show in addition fragments of metamorphosed, disrupted and deformed mafic dykes, which occur in most quarries. However the interpretation could not reveal whether the dykes were disrupted during the above mentioned deformation of the migmatised gneisses, or during a later phase of deformation.

\section{Illustration of granulite facies overprint with the analytical plotter}

As mentioned in the introduction, the clean quarry exposures in the Palghat Gap display effects of static, incomplete, prograde granulite facies metamorphism, during which hornblende and biotite were partially converted to hypersthene, and the overall grain size was increased by recrystallisation. Geological photogrammetry is well suited for documentation of this type of metamorphic transitions, because the hypersthenebearing rocks and their boundaries can best be identified on fairly recent quarry exposures. Hypersthene readily breaks down under intermediate metamorphic conditions to minute chlorite particles, which in turn impose a greasy green-brown tinge on the hypersthenebearing areas, so that they stand out from amphibolite facies areas after exposure to air and humidity for a few weeks. Progressive weathering then indiscriminately darkens the exposures and finally conceals the metamorphic transitions.

Figs 3-7 show that the areas of granulite facies transformation vary greatly in size, from most of a quarry down to a few centimetres, and that the partial conversion may occur as irregular patches (Fig. 4), or as thin discordant bands (Figs 3 and 6). Figs 4 and 6 also illustrate that the conversion seems to be enhanced in the most mafic lithologies; mafic dykes, amphibolites and dioritic gneisses may be in granulite facies, while the immediately adjacent tonalitic gneiss only contains smaller areas of granulite facies, and granite none at all (Fig. 5). Fig. 6 also shows a coarse-grained, hypersthene-bearing pegmatitic area of mobilisate along the granulite facies gneiss. This indicates that local partial melting occurred together with the granulite facies transformation.

Figs 3 and 6 show in addition that the granulite facies metamorphism cuts deformed migmatite structures and was not itself accompanied by penetrative deformation - note for example that all lithological units can be correlated across the recrystallised granulite facies zone on Fig. 6. The analysis with the analytical plotter therefore suggests that the granulite facies metamorphism at this locality was not the culmination of the first tectonometamorphic episode related to migmatisation of the gneisses, but an independent and later event.

Figs 3-7 also reveal other syn- and post-granulite facies events. Fig. 5 shows a fine-grained, dark grey alkaline dyke. It can be seen that the dyke is undeformed, and that it has cuspate margins which indicate that it was intruded into hot country rocks - perhaps at the time of, or shortly after granulite facies metamorphism. These dykes are very common in the Palghat Gap area. Also on Fig. 5, there are small areas of late, white to pinkish granitic rocks adjacent to the alkaline dyke, which may likewise have formed during the granulite facies episode.

Fig. 7 shows numerous irregular pegmatites. Along their margins the granulite facies rocks (which occur in the entire quarry area) are retrograded to amphibolite facies. Similar pegmatites also occur on Figs 3-6 where they cut all other rock types. Fig. 4 (upper left) and Fig. 6 (lower right) furthermore illustrate that small displacements have often taken place along the pegmatites.

\section{Conclusions}

Geological photogrammetry at close range, using the multi-model software, greatly aided the geological analysis of the outcrops and provided precise and detailed visual documentation - sometimes down to the size of individual crystals - of many important aspects of the geological evolution in the Palghat Gap area. This documentation could not have been achieved in any other way during the short period of field work. The method provides unbiased data which can be reinterpreted by another geologist, and when employed in quarries also provides a means of preserving a locality for future 


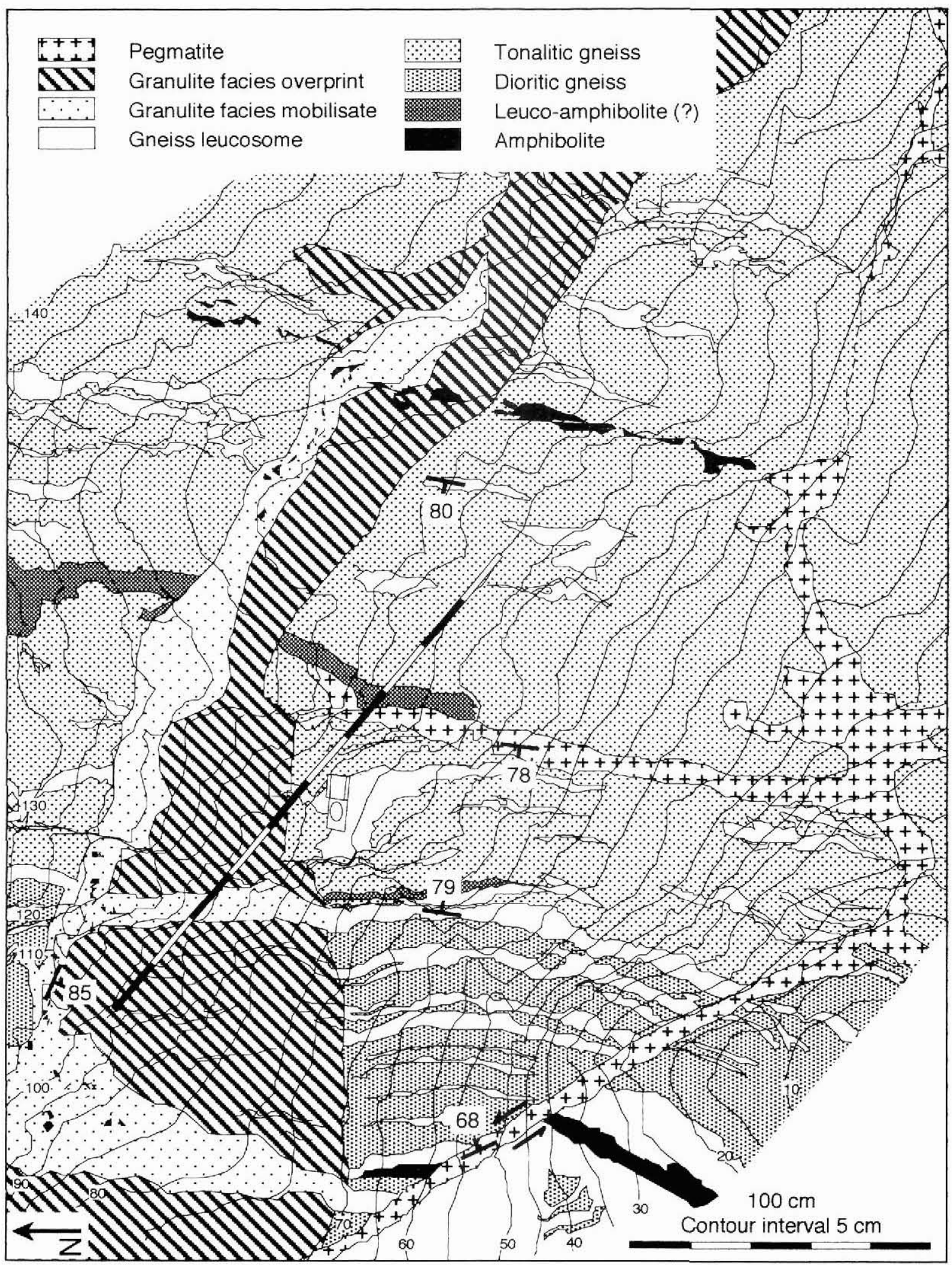

Fig. 6. Map at scale 1:25, quarry at Nemmara. Close-up geology at the feet of the geologist, taken with the camera axis plunging obliquely downwards. Note the discordant area of granulite facies and granulite facies mobilisate, indicating partial melting. Right-lateral displacement has occurred along a late pegmatite (lower right). The rule is $2 \mathrm{~m}$ long. 


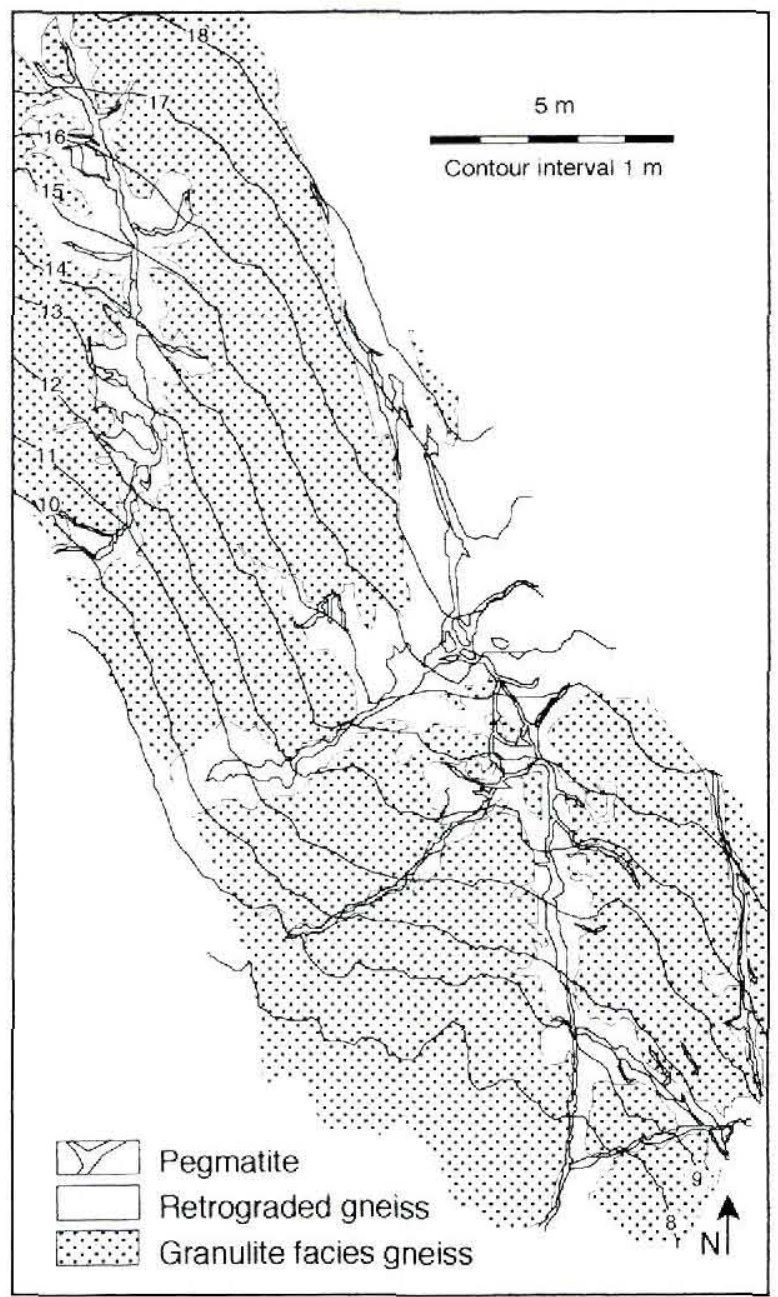

Fig. 7. Steep quarry face near Sangam College, scale 1:200, photographed with horizontal camera axis. The flat area to the north-east above the quarry face is concealed from the view of the camera. The quarry consists of tonalitic gneisses in granulite facies. Retrogression from granulite to amphibolite facies has taken place along the margins of late pegmatites.

analysis in the analytical plotter, irrespective of subsequent removal of the rocks themselves or degradation of visible geological detail by weathering. The method provides very flexible means of presentation in terms of scale and type of projection, and the plot data can easily be edited using commercial graphics applications for small computers, if so desired.
Close-range photogrammetry employing ordinary small-frame cameras and multi-model software (Dueholm, 1992) has potential use in many other situations where three-dimensional documentation is required, e.g. during detailed prospecting for economic minerals where precise correlation of local geology and sample localities is often wanted, or in geography, biology, archaeology, or architecture.

Acknowledgements. The author thanks G. R. Ravindra Kumar, Centre for Earth Science Studies, Trivandrum, for the invitation to visit South India, discussions in the field and comments to an earlier version of this paper, and Venkatesh Raghavan for cooperation and discussions in the field. The field work was supported by the Government of India (grant ES/23/063/88 to G. R. Ravindra Kumar) and by the Danish Natural Science Research Council (grant to the author).

\section{References}

Dueholm, K. S. 1992: Geologic photogrammetry using standard small-frame cameras. Rapp. Gronlands geol. Unders. 156 (this volume).

Dueholm, K. S. \& Garde, A. A. 1986: Geological photogrammetry using standard colour slides, Rapp. Gronlands geol. Unders. 130, 69-74.

Garde, A. A. 1990: Thermal granulite-facies metamorphism with diffuse retrogression in Archaean orthogneisses, Fiskefjord, southern West Greenland. J. metamorphic Geol. 8, 663-682.

Raith, M., Srikantappa, C., Ashamanjari. K. G. \& Spiering, B. 1990: The granulite terrane of the Nilgiri Hills (southern India): Characterization of high-grade metamorphism. In Vielzeuf, D. \& Vidal, P. (ed.) Granulites and crustal evolution, 339-365. Dordrecht: Kluwer.

Radhakrishna, B. P. 1983: Archaean granite-greenstone terrain of the South Indian Shield. In Naqvi, S. M. \& Rogers, J. J. W. (ed.) Precambrian of South India. Mem. geol. Soc. India 4, 1-46.

Ravindra Kumar, G. R. \& Raghavan, G. R. 1992: The incipient charnockites of transition zone, granulite zone and khondalite zone of South India: contrasting mechanisms and controlling factors. J. geol. Soc. India 39, 293-302.

Soman, K.. Thara, K. G., Arakelyants, M. M. \& Golubyev, V. N. 1990: Mineral ages of pegmatites from the Palghat Gap region in Kerala and their tectonic significance. J. geot. Soc. India 35, 82-86.

Subramanian, K. S. \& Muraleedharan, M. P. 1985: Origin of the Palghat Gap in South India - a synthesis. J. geol. Soc. India 26, 28-37. 